\title{
Future Land-Use Land-Cover Scenarios for the Flint River Watershed in Northern Alabama Using the Prescott Spatial Growth Model
}

\author{
Wubishet Tadesse ${ }^{1 *}$, Stephanie Whitaker ${ }^{2}$, William Crosson ${ }^{3}$, Constance Wilson ${ }^{4}$ \\ ${ }^{1}$ Department of Biological and Environmental Sciences, Alabama A \& M University, Huntsville, USA \\ ${ }^{2}$ Tennessee Department of Environment and Conservation, Nashville, USA \\ ${ }^{3}$ National Space Science and Technology Center, Universities Space Research Association, Huntsville, USA \\ ${ }^{4}$ Department of Community and Regional Planning, Alabama A \& M University, Huntsville, USA \\ Email: "wubishet.tadesse@aamu.edu
}

Received 6 May 2015; accepted 14 July 2015; published 17 July 2015

Copyright (C) 2015 by authors and Scientific Research Publishing Inc.

This work is licensed under the Creative Commons Attribution International License (CC BY).

http://creativecommons.org/licenses/by/4.0/

(c) $\underset{\mathrm{EY}}{\mathrm{E}}$ Open Access

\section{Abstract}

A changing mosaic of natural vegetation and human land uses has evolved within and around the Flint River Watershed (FRW) in Alabama and Tennessee over the past several decades. To determine the cause of change and linkage between human activities and environmental change can prove problematic. Subsequently, there is a need to produce projections of future environments based on planning instruments and socio-economic parameters. Scenarios of potential future land use land cover (LULC) change are required in order to better manage potential impacts on many environmental issues. This study creates future scenarios for the year $\mathbf{2 0 3 0}$ from baseline land use of 2001, relative to three projected land use scenarios which include differences related to conservation, planning, and development. The future growth scenarios were created using the ArcGIS tool, Prescott Spatial Growth Model (PSGM). The model allows users to build different future growth scenarios based on socio-economic projections such as population, employment and other controlling factors. The simulation results indicate that LULC changes associated with future urbanization can increase by $\sim 23 \%-43 \%$ within the FRW, which will lead to significant environmental issues if not managed properly. The overall analysis and model results demonstrate the ability of future growth scenarios to explore and evaluate options for a future environment. Spatial modeling and analysis tools, such as PSGM, provide a powerful approach to evaluate potential impacts of LULC change in the future and should be used to manage urbanization in areas with more intense development.

\footnotetext{
"Corresponding author.
}

How to cite this paper: Tadesse, W., Whitaker, S., Crosson, W. and Wilson, C. (2015) Future Land-Use Land-Cover Scenarios for the Flint River Watershed in Northern Alabama Using the Prescott Spatial Growth Model. Journal of Geographic Information System, 7, 319-327. http://dx.doi.org/10.4236/igis.2015.74025 


\section{Keywords}

\section{Prescott Spatial Growth Model, Land Use Land Cover}

\section{Introduction}

Scenarios, as defined by the Intergovernmental Panel on Climate Change [1], are "plausible and often simplified descriptions of how the future may develop based on a coherent and internally consistent set of assumptions about driving forces and key relationships". Scenario analysis is accomplished by using a process model and land-use data to produce a representation of the physical manifestations of scenario characteristics. Scenarios are usually conducted over long time periods and develop a range of driven perspectives, which are analyzed in detail for their consequences or benefits. In this study, three development scenarios representing future land use in the Flint River watershed in northern Alabama, USA were created using the Prescott Spatial Growth Model (PSGM). The three development scenarios are conservation growth, plan trend and development growth.

\section{Description of PSGM}

The PSGM was developed at Prescott College (AZ) in collaboration with National Aeronautics and Space Administration (NASA) and is a dynamic process model with a raster-based structure. The PSGM is an ArcGIS 9.× compatible application that assigns future growth into available land based on user-defined parameters [2]. The model allows users to build different future growth scenarios based on socio-economic projections such as population, employment and other controlling factors. The PSGM is a grid-based model that is projective, not predictive. Several inputs are needed for the model to run, including developable land, population and employee growth projection and suitability rules. A network of primary and secondary roads is needed as input into the model to show areas of existing transportation networks. The projected 2030 Transportation Plan for the City of Huntsville was used as a guide when inspecting the output of the PSGM. The 2030 Transportation Plan is a comprehensive review of the area transportation network and modes of urban mobility, resulting in the identification of projects and programs to be implemented in 2030 [3].

One of the input parameters, developable land, is in the form of a binary grid indicating land grid cells suitable for accepting future growth. Growth projection is specified in terms of acres consumed, for each projected year for each developed land use type. The PSGM allocates projected population and employment growth for specific projection years to user-specified land use categories [4]. User-defined suitability rules define where the future growth should be placed. This allocates the new growth onto the user-specified developable land grid, in the order of 1 to 10 , least to most suitable land. The output of the model is a series of growth grids, one for each projection year and land use type, showing the anticipated pattern of future growth. The model also combines these individual grids into a single suitability grid in order to statistically analyze and compare different growth scenarios more easily [4].

The successful function of the PSGM is dependent on the development of rule sets. For each land use class being assessed, a separate rule set is created. The different rules sets are run consecutively letting each rule set allocate land based on available area and priority. There is no limit on the number of rules in a scenario or a rule set [2]. Using the inputs and rule sets, simulations were performed for three different growth scenarios in this study reflecting changes in patterns of growth, development practices and constraints [5].

The PSGM has been previously used to model growth projections for various counties in the Atlanta, Georgia region [2], which has experienced significant land use changes and increased population over the years. The intent of the study was to validate the performance of the PSGM through comparison of scenarios generated with growth projections and those generated using actual growth for the time period. The validation study determined that the PSGM provides exceptional flexibility and good overall performance in projecting land use in the study area.

\section{Materials and Methods}

\subsection{Study Area}

The Flint River watershed (FRW) (Hydrologic Unit Code: 06030002) encompasses approximately 1445 Square 
km in Madison County, Alabama, and Lincoln County, Tennessee (Figure 1). The majority of the watershed is in Madison County and drains into the Tennessee River from which the City of Huntsville, Alabama receives its public drinking water. There are nine water bodies within the FRW currently listed on the US-EPA 303 (d) impaired water quality list [6]. The general land uses in the watershed are (with areas in $\mathrm{km}^{2}$ and $\%$ of watershed): Forest 425 (30\%), Cropland 360 (25\%), Pasture 400 (28\%), Mixed 120 (8\%) and Urban $120(8 \%)$, which is increasing by $19 \mathrm{~km}^{2} /$ year $(1.5 \%)$ [7]. The land use is agricultural with row crops and livestock production as major farm enterprises. Madison County is one of the fastest growing counties in Alabama, growing from a population of 238,912 in 1990 to 327,744 in 2009 [8]. Madison County's land use is over 30\% urban in many of the Flint River's sub-watersheds, and is estimated that by 2020 more than $50 \%$ of the county will be developed for urban use, reaching far into the FRW [9].

The Flint River has a watershed management plan that was developed by the Tennessee Valley Authority, the Madison Soil and Water Conservation District, and the Madison County Watershed Advisory Committee. The plan is based on several years of work by various federal, state, and local organizations and citizens and on currently available data provided by a number of citizens groups [7]. The primary issues described in the plan are uncontrolled urban development in the watershed and associated water quality and habitat degradation; hydrologic alterations of the river due to storm water from increased impervious surfaces, and loss of riparian forests and the associated degradation of habitats and loss of the river's scenic beauty. The plan has not been revised since May 2008 therefore, new research information on the FRW is needed to enable an update to the watershed management plan.

The growing population is placing heavy and divergent demands on the FRW. For example, the visual interpretation of the National Land Cover Dataset (NLCD) change between 1992 and 2006 (Figure 2) shows how much the watershed has been developed in just 14 years. Urban land use shown in red, increased from $0.98 \%$ in 1992 to $8.7 \%$ in 2006 with most development occurring around existing roads.

Knowing where the FRW may develop in the future is significant to create better management practices and ensure that quality water resources are available in the future. While conservation efforts have often focused on maximizing the quantity of land conserved, research efforts in landscape ecology have shown that the spatial pattern of land conversions can have a significant effect on the function of ecological processes [10]. From this we can determine what policies should be implemented to fight degradation of sensitive sub-basins affected by urbanization.

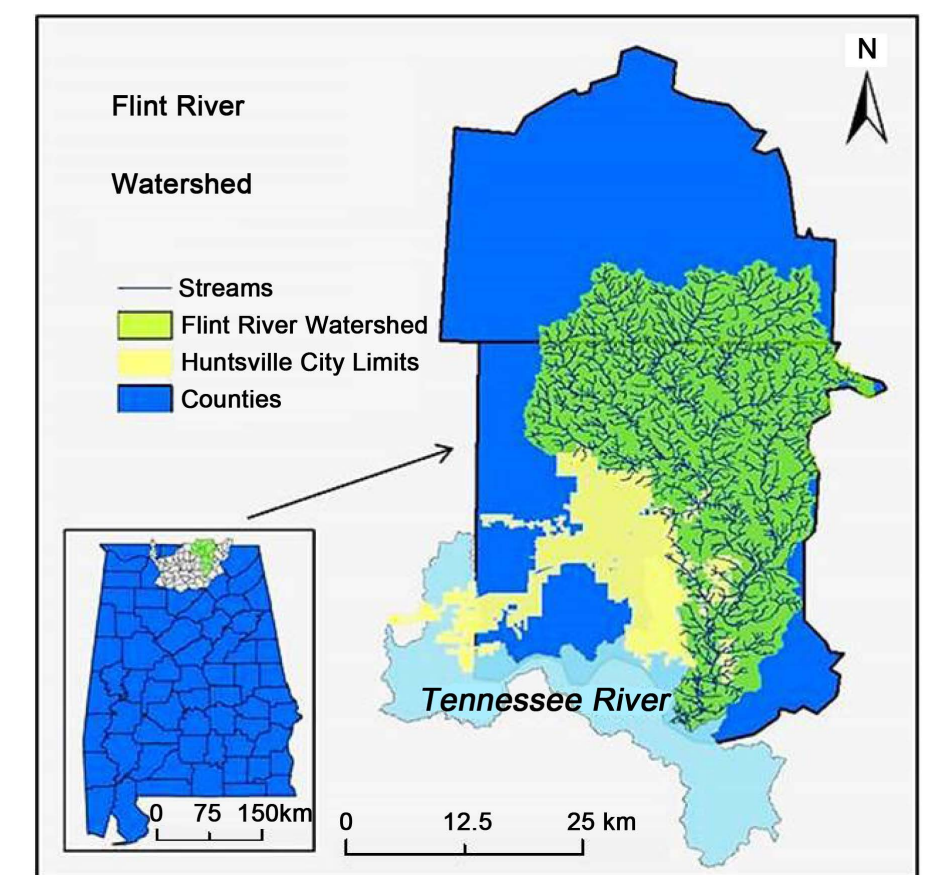

Figure 1. Map showing the location the flint river watershed in northern Alabama and southern Tennessee. 


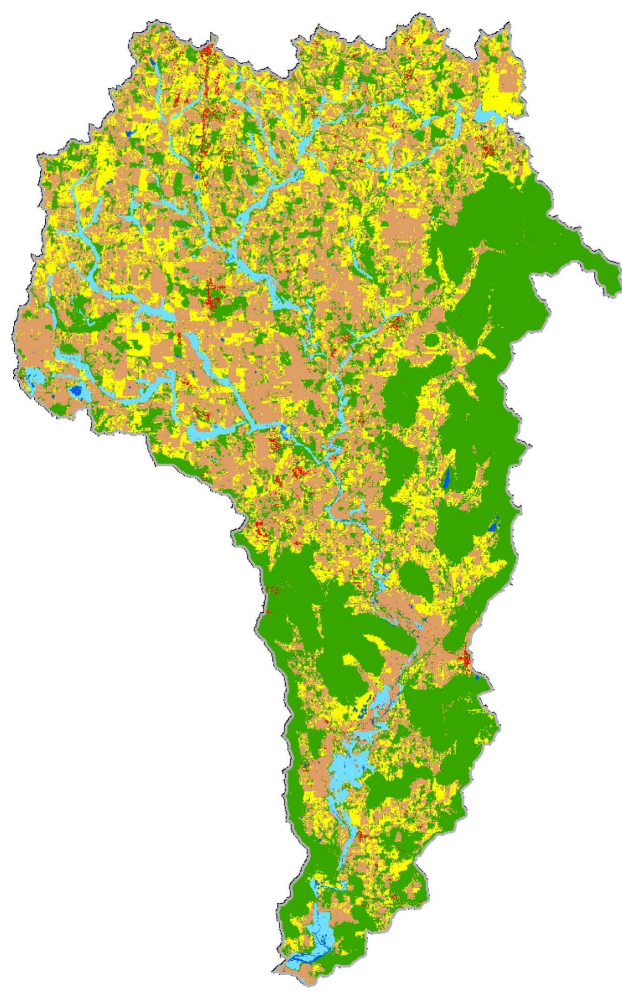

(a)

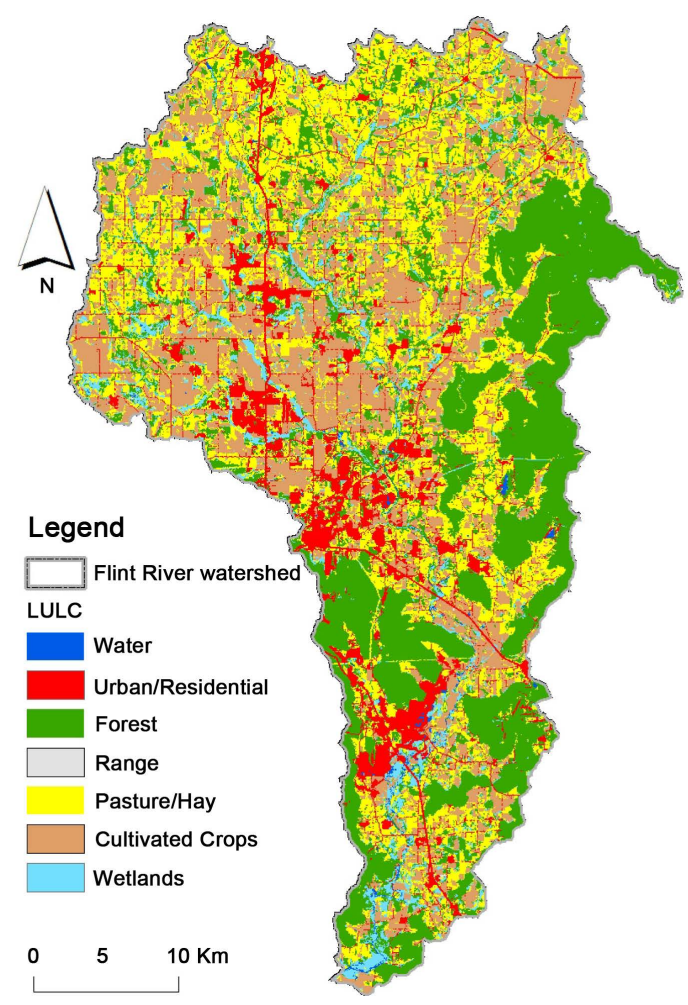

(b)

Figure 2. National Land Cover Dataset (NLCD) (a) 1992 and (b) 2006 for FRW.

\subsection{Data and Model Setup}

The three alternative-future scenarios produced by the PSGM are conservation growth, plan trend, and development growth. The conservation growth places greater priority on ecosystem protection and restoration, although still reflecting a plausible balance between ecological, social, and economic considerations. Plan trend assumes existing land use plans are implemented as written, with few exceptions, and recent trends continue. The development growth, which has the least conservation, assumes current land use policies are relaxed and has a greater reliance on land and water use [5]. To portray these different scenarios the input data, developable land layer and suitability rules vary among the scenarios.

The time steps for these future growth scenarios are 2000 to 2007 and 2007 to 2030, building off Census data for 2000. Projections for 2007 were created in order to validate the model. County-level data obtained from the U.S. Census report was used to create population and employment tables. Population and employment data for 2000, 2007 and 2030 for each county and area in acres of commercial and residential land was used to determine the input parameters for the model. The 2007 population and employment data was collected from the American Community Survey. Input for residential land use data includes Dwelling Units per Acre (DUAC) for each county and Persons per Housing Unit (PPHU). DUAC values were set as 2.75, 2.5 and 2.25 for Lincoln County (TN) and 3.25, 3 and 2.75 for Madison County (AL) in the conservation, plan and development growth scenarios respectively. The PPHU value was 2.0 for both counties in each of the three scenarios. Commercial land use data included Gross Square Footage per employee (GSF) and Floor Area Ratio (FAR) for each county in the study area. The GSF of commercial land was generalized in this analysis to be 250 for Lincoln County and 350 for Madison County. For both counties FAR values were calculated from jobs per acre and were 0.9, 0.6 and 0.3 in the conservation, plan and development scenarios respectively. The model uses a spreadsheet-like interface to calculate acres consumed of future commercial and residential land from inserted values of DUAC, PPHU, GSF, FAR, population and employment for each time step (Table 1 and Table 2).

The NLCD serves as the definitive Landsat-based, 30 meter resolution, and land cover database for the Nation [11]. NLCD products are created by the multi-resolution land characteristics (MRLC) consortium, a part 
Table 1. Increase in number of jobs, 2000-2007 and projected job increases over 2007-2030 for Lincoln county, TN and Madison county, AL. The PSGM calculated acres consumed of future commercial growth for each scenario.

\begin{tabular}{cccccc}
\hline Time Step & County & Job Increase & $\begin{array}{c}\text { Consumed } \\
\text { Conservation (Acre) }\end{array}$ & $\begin{array}{c}\text { Consumed } \\
\text { Plan (Acre) }\end{array}$ & $\begin{array}{c}\text { Consumed } \\
\text { Development (Acre) }\end{array}$ \\
\hline $2000-2007$ & Lincoln & 1067 & 6 & 10 & 20 \\
$2000-2007$ & Lincoln & 3992 & 25 & 38 & 315 \\
$2000-2007$ & Madison & 23,594 & 210 & 1332 & 631 \\
$2007-2030$ & Madison & 99,484 & 888 & 2664 \\
\hline
\end{tabular}

Table 2. ncrease in population, 2000-2007 and projected population increases over 2007-2030 for Lincoln county, TN and Madison county, AL. The PSGM calculated acres consumed of future residential growth for each scenario.

\begin{tabular}{cccccc}
\hline Time Step & County & Job Increase & $\begin{array}{c}\text { Consumed } \\
\text { Conservation (Acre) }\end{array}$ & $\begin{array}{c}\text { Consumed } \\
\text { Plan (Acre) }\end{array}$ & $\begin{array}{c}\text { Consumed } \\
\text { Development (Acre) }\end{array}$ \\
\hline $2000-2007$ & Lincoln & 1393 & 253 & 278 & 309 \\
$2000-2007$ & Lincoln & 2730 & 496 & 546 & 606 \\
$2000-2007$ & Madison & 37,096 & 5707 & 6182 & 6744 \\
$2007-2030$ & Madison & 75,358 & 11,593 & 12,559 & 13,701 \\
\hline
\end{tabular}

nership of Federal agencies led by the USGS. The 2001 NLCD for both counties within the FRW was used as the land use input grid for projected growth. The 2001 land use distinguishes 16 different classes but in the study area the perennial ice/snow land use was excluded leaving the following land use classes; open water, developed open space, developed low intensity, developed medium intensity, developed high intensity, barren land, deciduous forest, evergreen forest, mixed forest, grassland, shrub, pasture/hay, cultivated crops, woody wetlands and emergent wetlands [11]. The NLCD was reclassified from the original 15 land use classes to 14 dominant classes for each county by merging the developed low intensity (DLI) land use with developed medium intensity (DMI) land use to form the residential land use category (DMLI). The DLI contains areas with a mixture of constructed material and vegetation and is composed of $20 \%$ to $49 \%$ of impervious surfaces. The DMI areas most commonly include single-family housing units and contain $50 \%$ to $79 \%$ of impervious surfaces. The developed high intensity (DHI) land use is here considered the commercial land use category. The DHI includes highly developed areas and are $80 \%$ to $100 \%$ covered by impervious surfaces.

The developable land grid, which contained valid values for cells that represent land use areas suitable for accepting future growth, was created from the 2001 NLCD layer. The developable land grid was different for all three scenarios but in no scenario contained areas classified as urban, developed open space or open water. The conservation scenario had a 50 foot buffer around the classified wetland areas that was excluded from the available land layer, thus conserving land within $50 \mathrm{ft}$ of wetlands. The developable land grid contained the forest, shrub, pasture, and agriculture land use classes for the conservation scenario and for the plan trend scenario the grid included these classes plus barren and grassland classes. For the development scenario the land available for development included all the land use classes except urban, developed open space and open water therefore, future growth could be allocated in many land use areas, including wetlands making this scenario have the least conserved land.

The suitability rules are defined in PSGM to guide the allocation of projected growth for residential and commercial land use. Each of the rules is used to create an individual suitability grid; when there is more than one rule the individual grids are added to create a composite suitability grid for that land use category [2]. The rules created in the three scenarios all used the same themes which included "in county", "near existing development", "near roads" and "random". The themes were used as the spatial reference for distance and are linked to the raster layer they describe. Weight of each rule specifies the importance of the rule relative to the rest by having a higher value it is more important therefore, growth will be allocated there first. The rule sets created (Table 3) were run consecutively in the model simulation, letting each rule set allocate land based on available area and priority. 
Table 3. Rules used for commercial and residential land in Lincoln and Madison counties for the conservation growth scenario.

\begin{tabular}{|c|c|c|c|c|}
\hline Rule Theme & $\begin{array}{c}\text { Commercial } \\
\text { Distance (Miles) }\end{array}$ & Weight & $\begin{array}{c}\text { Residential } \\
\text { Distance (Miles) }\end{array}$ & Weight \\
\hline In County - develop land in respective county first & 10 & 7 & 10 & 7 \\
\hline Near roads - Within x miles of road network & 0.1 & 5 & 0.5 & 1 \\
\hline $\begin{array}{l}\text { Within x miles of existing development } \\
\text { of same type (commercial or residential) }\end{array}$ & 1 & 5 & 1 & 5 \\
\hline $\begin{array}{c}\text { Random-allows spontaneous } \\
\text { development in available land layer }\end{array}$ & Not used & 1 & Not used & 1 \\
\hline
\end{tabular}

PSGM's growth allocation module assigns growth (in acres) to the composite suitability grid. As land use is allocated, it is removed from consideration by the model in the allocation of other land use needs. The output grids of the model were merged by land use type and year of growth to display the complete LULC data for assessment for each county and time step. The 2007 projected land use was only used to validate the performance of the model.

\section{Results}

Using the PSGM parameter inputs and rule sets described in the previous sections, the conservation, plan and development growth simulations were performed starting from the same NLCD 2001 observed data to predict land use in the year 2030. The initial land use output was for the entirety of Lincoln County, Tennessee and Madison County, Alabama (Figure 3) but was extracted by the FRW boundary. The difference between the baseline land use and the future growth scenarios is evident in Figure 3 and quantified in Table 4, which, shows percent of land base composed of water, urban/residential, forest, range, pasture, cultivated crops and wetland. The three alternative future scenarios create different patterns of LULC change in the FRW which was used to evaluate the increases of urbanization between scenarios. Table 4 shows significant differences in land use change between the three scenarios. The conservation growth scenario places greater priority on ecosystem protection compared to the other scenarios by having less of the forest, pasture and agricultural and being turned into urban land, and it also conserved the wetlands. The plan trend scenario was closely related to the conservation growth but more areas of the forest, pasture and agricultural land use was consumed by urban development. Moreover, the development growth had more of a randomized development causing more of the forest, pasture and agricultural land use to be consumed by urban growth as well as wetlands. Differences between scenarios are smaller within the FRW boundary than for the entire study area because the majority of the land use being developed is near the City of Huntsville, which is mostly located outside of the watershed.

\section{Validation}

Projections of future state cannot be validated, but the accuracy of the model can be evaluated in hind-cast mode, in which projections are made from some past starting point, and results compared with observed LULC data at the simulation end time [12] For model validation the NLCD 2001 data were used to project 2007 land use for the three scenarios. The projected 2007 land use from the PSGM output was compared to the observed NLCD 2006 data to determine the accuracy of the projections with respect to the observational data. The 2007 LULC projections were all similar to the observed 2006 LULC but the conservation growth projection was the most accurate in comparison to the other scenarios (Table 5). For residential land use, the percent differences between observed and projected values were $0.45,0.55$ and 0.62 for conservation, plan and development scenarios, respectively. The commercial land use values had smaller differences with $0.01,0.02$ and 0.04 for the three scenarios respectively. Land use data standardization is an important consideration when comparing remotelysensed data [2]. The projected 2007 and observed 2006 land use data cover the same geographic area and are classified into the same land use types and have the same resolution. However, there are minor differences in the 2001 and 2006 NLCD data sets that complicate the validation shown in Table 5. For example, the difference in the coverage of Open Water between the two land use data sets is evident; the three land use scenarios use the 2001 baseline, of which 741.87 ha is classified as Open Water. This land use does not change in any of the sce- 

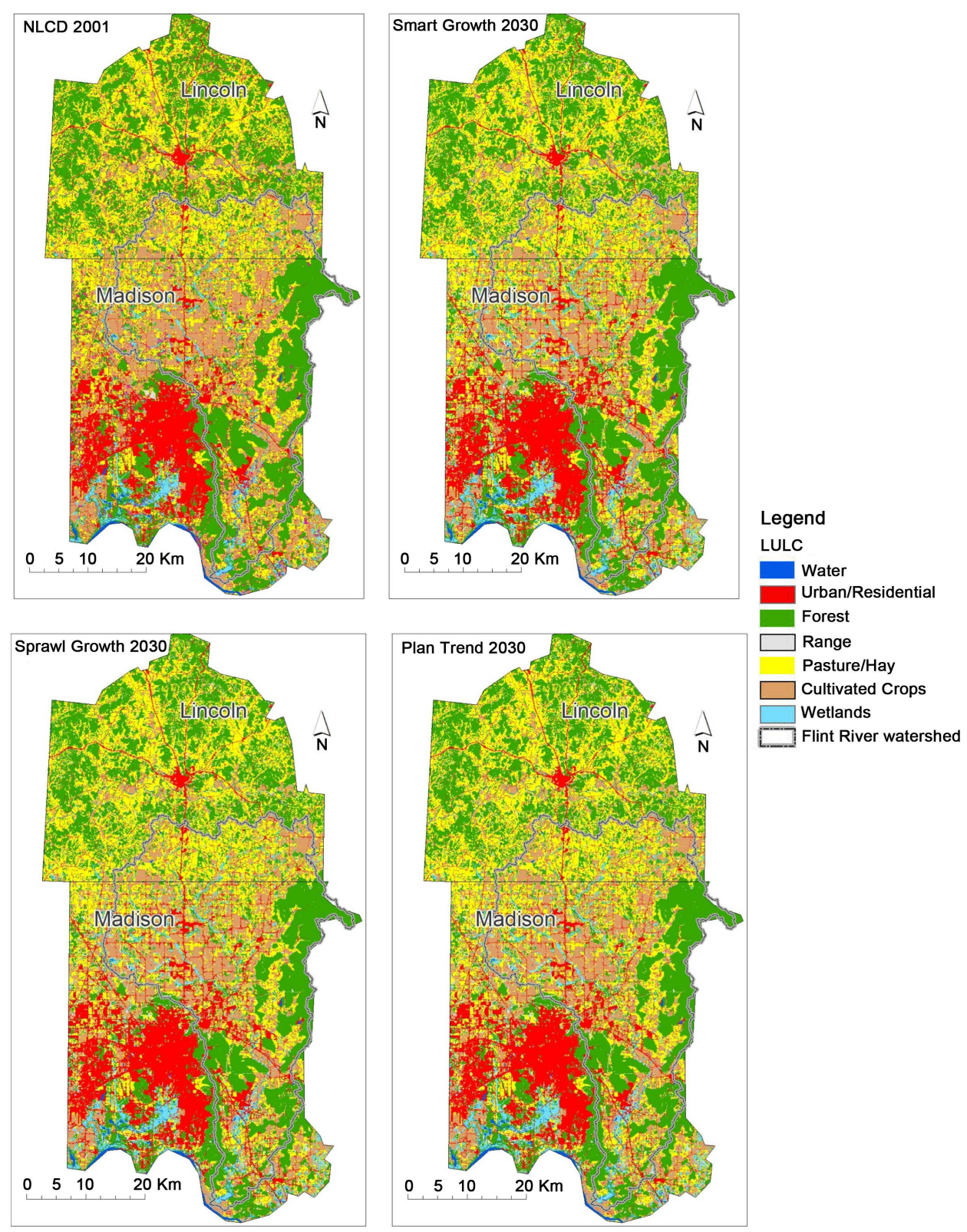

Figure 3. Distribution of land use for the three future growth scenarios and the 2001 land use baseline for Lincoln county, Tennessee, and Madison county, Alabama.

Table 4. Percentage of total area and percentage relative change relative to the 2001 baseline for the dominate land uses in the River watershed (+values indicate an increment from baselione conditions).

\begin{tabular}{ccccc}
\hline Land Cover & \multicolumn{4}{c}{ Percent Total Area and Percent Change } \\
\cline { 2 - 5 } & 2001 Baseline & Smart & Plan & Sprawl \\
Water & 0.51 & $0.51(0.0)$ & $0.51(0.0)$ & $0.51(0.0)$ \\
Urban/residential & 7.0 & $9.81(+40.14)$ & $10.01(+43.00)$ & $11.43(+63.29)$ \\
Forest & 31.23 & $29.99(-3.97)$ & $29.95(-4.10)$ & $29.76(-4.71)$ \\
Range & 4.79 & $4.71(-1.67)$ & $4.68(-2.3)$ & $4.6(3.97)$ \\
Pasture & 27.65 & $26.8(-3.08)$ & $26.73(-3.35)$ & $26.09(-5.65)$ \\
Cultivated crops & 25.18 & $24.54(-2.55)$ & $24.48(-2.78)$ & $24.02(-4.63)$ \\
Wetland & 3.65 & $3.65(0)$ & $3.65(0)$ & $3.59(-1.64)$ \\
\hline
\end{tabular}


Table 5. Increase in population, 2000-2007 and projected population increases over 2007-2030 for Lincoln county, TN and Madison county, AL. The PSGM calculated acres consumed of future residential growth for each scenario.

\begin{tabular}{ccccccccc}
\hline Land Use Class & $\begin{array}{c}\text { NLCD } \\
2006(\mathrm{ha})\end{array}$ & $\begin{array}{c}\text { Basin } \\
\%\end{array}$ & $\begin{array}{c}\text { Conservation } \\
2007(\mathrm{ha})\end{array}$ & $\begin{array}{c}\text { Basin } \\
\%\end{array}$ & $\begin{array}{c}\text { Plan } \\
2007 \text { (ha) }\end{array}$ & $\begin{array}{c}\text { Basin } \\
\%\end{array}$ & $\begin{array}{c}\text { Development } \\
2007 \text { (ha) }\end{array}$ & $\begin{array}{c}\text { Basin } \\
\%\end{array}$ \\
\hline Open water & 708.12 & 0.49 & 741.87 & 0.51 & 741.87 & 0.51 & 741.87 & 0.51 \\
Developed open space & 8724.96 & 5.99 & 8302.68 & 5.70 & 8302.68 & 5.70 & 8302.68 & 5.70 \\
Residential & 3791.61 & 2.60 & 4453.65 & 3.06 & 4588.47 & 3.15 & 4696.74 & 3.23 \\
Commercial & 137.52 & 0.09 & 150.03 & 0.10 & 162.18 & 0.11 & 202.77 & 0.14 \\
Barren land & 43.47 & 0.03 & 45.18 & 0.03 & 44.73 & 0.03 & 44.91 & 0.03 \\
Deciduous forest & 39538 & 27.16 & 39,500 & 27.13 & 39466 & 27.11 & 39460 & 27.10 \\
Evergreen forest & 1901.88 & 1.31 & 1941.75 & 1.33 & 1938.33 & 1.33 & 1934.91 & 1.33 \\
Mixed forest & 2393.82 & 1.64 & 2423.34 & 1.66 & 2421.54 & 1.66 & 2421.18 & 1.66 \\
Shrub & 5191.83 & 3.57 & 5173.11 & 3.55 & 5168.70 & 3.55 & 5160.15 & 3.54 \\
Grassland & 2066.85 & 1.42 & 1742.67 & 1.20 & 1725.75 & 1.19 & 1723.86 & 1.18 \\
Pasture & 39796.92 & 27.34 & 39614.31 & 27.21 & 39549.60 & 27.17 & 39494.79 & 27.13 \\
Cultivated crops & 35970.57 & 24.71 & 36187.29 & 24.86 & 36166.05 & 24.84 & 36114.66 & 24.81 \\
Woody wetlands & 5283.81 & 3.63 & 5276.43 & 3.62 & 5276.43 & 3.62 & 5254.02 & 3.61 \\
Emergent wetlands & 33.12 & 0.02 & 30.24 & 0.02 & 30.24 & 0.02 & 30.06 & 0.02 \\
Total & 145582.2 & 100 & 145582.2 & 100 & 145582.2 & 100 & 145582.2 & 100 \\
\hline
\end{tabular}

narios, but is slightly higher than the 708.12 ha classified in the 2006 NLCD. Similarly, there are minor differences in the Emergent Wetlands class.

\section{Conclusions}

Specifically, the assessment suggests that an approximate $23 \%$ increase in urbanized area in the conservation scenario will occur by 2030 within the FRW. Within the conservation scenario, the areas with the largest increase in development were located near the developing cities of Moores Mill and Meridianville Alabama. For the plan scenario, urbanized area increased by $\sim 25 \%$, and areas with the largest increase in development were the same as the conservation scenario. The development scenario had the largest increase in urban land use of $\sim 43 \%$, with the largest increase in development near the Huntsville City Limits and developing cities adjacent to major roads. The simulation results indicate that LULC changes associated with future urbanization can increase by $\sim 23 \%-43 \%$ within the FRW which will lead to significant environmental issues if not managed properly.

The analysis reveals that the PSGM is an effective tool in forecasting scenario based land use change over a 30 -year period and can be run with readily available data. The validation results indicate that with accurate input parameters and reasonable population and employment forecasts, land use change can be projected into the future with acceptable accuracy. The uncertainties in estimating PSGM parameters such as dwelling units per acre and jobs per acre and errors in population and employment forecasts have a substantial impact on the ability of the model to simulate urban land use changes. The overall analysis and model results demonstrate the ability of future growth scenarios from baseline digital land use data to explore and evaluate options for a future environment. Spatial modeling and analysis tools such as PSGM provide a powerful approach to evaluate potential impact to LULC change in the future and can be used to manage development in areas with more intense urbanization

\section{Acknowledgements}

The authors gratefully acknowledge Drs. David Mays and Dawn Lemke for thorough review of this manuscript. We also thank Heather Howell, Allison Bohlman, Helen Czech, Dr. Raghavan Srinivasan, Mr. Hoyt Johnson 
and Mr. Howard Ward for their endless support of information pertaining to the research. Also, the United States Department of Agriculture, National Institute of Food and Agriculture Award No. 2008-51130-04899 and National Aeronautics and Space Administration Graduate Student Research Program Fellowship for their financial support to complete this work.

\section{References}

[1] Intergovernmental Panel on Climate Change (IPCC) (2001) Climate Change 2001: The Scientific Basis. In: Houghton, J., Ding, Y., Griggs, D.J., Noguer, M., van der Linden, P.J., Dai, X., Maskell, K. and Johnson, C., Eds., Contribution of Working Group I to the Third Assessment Report of the Intergovernmental Panel on Climate Change, Cambridge University Press, Cambridge, 881.

[2] Estes Jr., M.G., Crosson, W.L., Al-Hamdan, M.Z., Quattrochi, D.A. and Johnson III, H. (2010) Validation and Demonstration of the Prescott Spatial Growth Model in Metropolitan Atlanta, Georgia. Urban and Regional Information Systems Journal, 22, 5-21.

[3] Planning Department of the City of Huntsville (PDCH 2011) Year 2030 Transportation Plan. Viewed 22 January 2011. http://www.hsvcity.com/Planning/mpo//docs/final2035plan.pdf

[4] Digital Comprehensive Plan Modeling Suite (DCPMS 2006) for ArcGIS 9.x. Version 2.2, User Manual. Blue Line Consulting Group.

[5] Kepner, W., Hernandez, M., Semmens, D. and Goodrich, D. (2008) The Use of Scenario Analysis to Assess Future Landscape Change on a Watershed Condition in the Pacific Northwest (USA). In: Petrosillo, I., Müller, F., Jones, K.B., Zurlini, G., Krauze, K., Victorov, S., Li, B.-L. and Kepner, W.G., Eds., Use of Landscape Sciences for the Assessment of Environmental Security, Springer, Berlin, 237-261.

[6] Environmental Protection Agency (2010) Our Built and Natural Environments: A Technical Review of the Interactions between Land Use, Transportation, and Environmental Quality. EPA 231-R10-002.

[7] Tennessee Valley Authority, Madison County Natural Resources Conservation Service, and Madison County Watershed Advisory Committee (2008) Flint River Watershed Management Plan. Revised May 2008.

[8] U.S. Department of Commerce Bureau of the Census, Population Estimates Division. 14 May 2010.

[9] Laymon, C. (2003) Environmental Assessment at County Scale. Viewed 10 October 2006. http://www.ghcc.msfc.nasa.gov/land/ncrst/ca.html

[10] Theobald, D., Spies, T., Kline, J., Maxwell, B., Hobbs, N. and Dale, V. (2005) Ecological Support for Rural Land-Use Planning. Ecological Applications, 15, 1906-1914. http://dx.doi.org/10.1890/03-5331

[11] United States Geological Survey (USGS) (2010) Seamless Server Data Warehouse. http://seamless.usgs.gov/

[12] Liu, Y., Gupta, E. and Wagener, T. (2008) Linking Science with Environmental Decision Making: Experiences from an Integrated Modeling Approach to Supporting Sustainable Water Resources Management. Environmental Modeling and Software, 23, 846-858. http://dx.doi.org/10.1016/j.envsoft.2007.10.007 